\title{
Direito civil (em crise) e a busca de sua razão antropocêntrica
}

\author{
Gustavo Pereira Leite Ribeiro*
}

Sumário: 1. Uma introdução; 2. Acepções do termo crise: o resgate do sentido originário; 3. Em busca da legitimidade do direito civil: a revolta dos fatos contra o código; 4. Superação do modelo codificado: a indispensabilidade do direito civil e sua razão antropocêntrica. Referências.

\begin{abstract}
Resumo: O artigo pretende demonstrar a possibilidade de perceber as principais transformações do direito civil contemporâneo como um indicativo de sua vitalidade. Além disso, destacar que as atuais mutações do direito civil apontam para o resgate da tutela da dignidade da pessoa humana.
\end{abstract}

Palavras-chave: Direito civil; Codificação; Crise; Legitimidade; Dignidade da pessoa humana.

\begin{abstract}
The article intends to demonstrate the possibility to perceive the main transformations of the civil law contemporary as indicative of its vitality. Moreover, to detach that the current changes of the civil law point with respect to the rescue of the guardianship of the dignity of the person human being.
\end{abstract}

Keywords: Civil law; Codification; Crisis; Legitimacy; Dignity of the person human being.

\section{Uma introdução}

O direito civil, desde suas remotas raízes romanas, passando pela formulação moderna das codificações, articula-se sobre um núcleo material constante, ocupado pelo tripé formado pela pessoa, família e patrimônio, sendo que seus principais caracteres foram se aperfeiçoando e se conservam como valor de herança tradicional. Do ponto de vista histórico-cultural, o direito civil apresenta-se como aquele setor da disciplina jurídica dotado de certa estabilidade, especialmente quando confrontado com o direito público, altamente sensível às contingências de ordem política e ideológica que atingem determinada sociedade no decorrer de sua existência (DE CUPIS, 1986, p.195).

O direito civil mantém, dessa forma, ao longo dos séculos, uma linha de continuidade histórica nos seus aspectos formais e materiais, estando menos sujeito a transformações bruscas (TOBEÑAS, 1961, p.77-78). Contudo, parece que sua es-

\footnotetext{
* Professor de Direito Civil no Centro Universitário UNA. Doutorando em Direito Privado pela Pontifícia Universidade Católica de Minas Gerais, com estágio de investigação na Faculdade de Direito da Universidade de Coimbra, Portugal. Bolsista da CAPES.
} 
tabilidade é gravemente ameaçada pelas transformações contemporâneas que atingem seu âmago, pois, num curtíssimo espaço de tempo, o direito civil vem sofrendo substanciais alterações, que atingem tanto sua estrutura como seu conteúdo, acabando naturalmente por ensejar certo estado de perplexidade nos juristas, que passam a proclamar sua crise (DE CUPIS, 1986, p.202-204).

Como bem adverte o professor italiano Michele Giorgianni, "são conhecidas as reações de consternação muitas vezes expressas pelos civilistas" diante das significativas transformações contemporâneas do direito civil, "como as de quem, retornando de uma longa ausência, encontrasse a sua casa invadida por gente estranha que derrubara muros e portas, modificara tapeçaria e móveis" (GIORGIANNI, 1998, p.36). A crise do direito é anunciada, por vozes autorizadas, com certo assombro e melancolia (vide RIPERT, 1953). Aliás, chegou-se inclusive a afirmar que, se o direito civil continuasse transformando-se substancialmente, acabaria mesmo por desaparecer (AZEVEDO, 1975, p.16).

No que tange a sua estrutura, presencia-se o declínio dos dogmas fundantes do movimento clássico de codificação, como a completude, a coerência e, obviamente, a segurança jurídica. Acredita-se que a proliferação das leis especiais ameaça a unidade do sistema privado, acabando por exigir o desenvolvimento de instrumental que facilite a compreensão e manipulação das possíveis relações entre os vários núcleos normativos fragmentados.

Evidencia-se a fragilidade da técnica legislativa rígida e casuística, que definitivamente não consegue dar tratamento adequado às novas situações que emergem das complexas relações sociais. A seu turno, ganham prestígio as cláusulas gerais, que não utilizam termos de conteúdo pré-fixado, mas de conteúdo determinável, o que acarreta uma maior possibilidade de adaptar a norma às situações de fato. Reconhece-se também a relevância e a prevalência normativa dos princípios jurídicos, especialmente daqueles de índole constitucional, na solução concreta dos litígios privados.

Enfim, as mudanças estruturais convergem para a valorização da atividade do intérprete, que não se limita mais à rasa e literal exegese. O intérprete passa a contribuir efetivamente para a construção da decisão justa em cada litígio concreto, participando ativamente do preenchimento do conteúdo da norma jurídica. Mais que isso, evidencia-se que somente através da atividade interpretativa é possível criar as condições necessárias para o diálogo e harmonização das diversas fontes normativas.

No que tange ao seu conteúdo, parece que as transformações são mais significativas. Percebe-se o declínio da proteção abstrata da pessoa, típica das primeiras codificações modernas, implementando-se a promoção da igualdade substancial, 
que reconhece as desigualdades fáticas e legitima seu tratamento diferenciado como medida de inclusão. Projeta-se a ampliação da proteção dos direitos de personalidade, com a conseqüente valorização da autonomia privada também nas relações de cunho existencial.

$\mathrm{Na}$ família, abandona-se o modelo matrimonializado e hierarquizado, de forte conteúdo patrimonial. Promove-se a igualdade entre os cônjuges e entre os filhos, reconhecendo-se, posteriormente, a pluralidade das entidades familiares, que passam a ser vistas como locus de afeto e de tutela do pleno desenvolvimento dos seus integrantes. Vivencia-se a desbiologização dos laços paterno-filiais, com a conseqüente valorização do melhor interesse da criança e a relativização da autoridade parental. A seu turno, percebe-se que as inovações biotecnológicas no campo da procriação humana acabam por exigir uma radical redefinição do sistema clássico de filiação.

No patrimônio, supera-se a concepção absoluta de propriedade através do reconhecimento de sua imanente função social. Percebe-se que o proprietário não tem apenas poderes, mas também deveres no exercício do seu direito; sendo que a destinação dada a sua propriedade deve harmonizar-se com os interesses sociais, sem que, contudo, isso leve ao exagero da coletivização dos bens. Supera-se também o caráter unitário e abstrato de sua disciplina jurídica, tendo em vista a pluralidade de modalidades da situação proprietária, dada a diversidade de seus objetos. Distinguem-se, dentre outros, regimes jurídicos voltados para o atendimento das intrínsecas peculiaridades da propriedade rural, da propriedade industrial, da propriedade urbana, da propriedade acionária, da propriedade dos bens de consumo, da propriedade intelectual.

Quanto ao contrato, o princípio fundamental da autonomia da vontade e seus principais corolários são amplamente mitigados. Torna-se freqüente a intervenção estatal na regulação do conteúdo do contrato, bem como na liberdade de escolha do parceiro contratual; medidas que objetivam claramente resguardar as legítimas expectativas dos contratantes em posição de vulnerabilidade, uma vez que se expande a utilização das técnicas massificadas de contratação - cláusulas contratuais gerais e contratos de adesão, que utilizam um esquema contratual predisposto por um dos contratantes e que, posteriormente, é oferecido ao outro para simples adesão. Além disso, atenua-se o rigor do princípio da obrigatoriedade contratual, com o conseqüente reconhecimento da admissibilidade da revisão judicial dos contratos, tendo em vista a constatação de excessiva onerosidade prestacional suportada por apenas uma das partes. Mais do que isso, o princípio da boa-fé objetiva reveste-se de extrema importância, passando a ocupar o centro da regulação, interpretação e execução dos contratos, assumindo definitivamente a posição ocupada outrora pelo princípio da autonomia da vontade. Impõem-se aos contratantes uma série de deveres 
de comportamento recíproco, a partir de parâmetros de lealdade, transparência, cuidado, auxílio e confiança.

Por fim, percebe-se uma valorização e ampliação da extensão da responsabilidade civil, que passa, inclusive, por um gradual processo de objetivação. O dever jurídico de recomposição de dano passa a fundar-se, cada vez mais, no risco inerente às atividades, pois se constatou que a demonstração da culpa do agente causador do dano, em inúmeras situações corriqueiras, tornava-se extremamente penosa ou até impossível, o que acabava impedindo qualquer tipo de reparação. Ultrapassa-se a noção de responsabilidade civil derivada exclusivamente de atos ilícitos, bem como aquela restrita à recomposição apenas de danos materiais, que fundamentavam a tímida disciplina do instituto jurídico de outrora.

Um olhar contemplativo sobre a paisagem e o horizonte do direito civil contemporâneo revela importantes questionamentos. Qual o significado da crise do direito civil? O que justifica as transformações do direito civil? O direito civil corre mesmo o risco de desaparecer?

As respostas a essas indagações não podem ser apresentadas de maneira simplista, devendo estar bem expostos e claros os seus pressupostos, tendo em vista a coetânea banalização da idéia de crise. Para tanto parece-nos adequado caminhar por três passos.

\section{Acepções do termo crise: 0 resgate do sentido originário}

É imprescindível deixar bem claro o sentido que será atribuído ao termo "crise", o que muitas vezes passa despercebido pelos seus manipuladores.

$\mathrm{Na}$ atualidade, o conceito de crise alcança uma extraordinária abrangência, que o faz perpassar por praticamente todas as esferas dos fenômenos que repercutem no nosso meio social. A propósito, afirma Gerd Bornheim que "o grande palco das crises chega a adensar-se de modo até espetacular no evolver da história, a ponto de se poder avançar que as palavras história e crise quase acabaram por fazer-se sinônimas" (BORNHEIM, 1996, p.47). E continua o autor: "No que concerne ao nosso tempo as crises parecem mudar substancialmente a sua fisionomia, seja pelo ineditismo de sua extensão como também pela radicalidade das metamorfoses que tudo se vê" (BORNHEIM, 1996, p.49).

Mais que isso, o termo passa a ostentar uma dimensão essencialmente negativa, conseqüência do seu uso corriqueiro. Toda crise seria em si mesma maléfica, apontando necessariamente para uma fatalidade, isto é, para a transição de uma época de prosperidade para outra de depressão ou decadência. Outras vezes a 
idéia de crise designaria um estado de dúvidas, aflições e incertezas, bem como uma conjuntura grave, tensa ou perigosa, ou, ainda, uma deficiência, penúria ou extinção.

No entanto, é curioso observar que a origem grega da palavra "crise" nada tem de intrinsecamente negativo. Etimologicamente, krisis, derivada do verbo grego krino, quer designar escolha, julgamento, decisão (BORNHEIM, 1996, p.49). Tal acepção encontra sua origem na medicina hipocrática, que utilizava a expressão para indicar uma transformação decisiva ocorrida no ponto culminante de uma doença, orientando o seu curso em sentido favorável ou não.

A crise apontaria tão-somente o momento determinante entre vida e morte, ensejando, ou melhor, exigindo um julgamento, uma escolha ou uma decisão pelo médico. Pode-se, portanto, dizer que a idéia de crise está ligada "a um momento decisivo no seio de um processo, a um momento em que as condições, mais ou menos conflitantes, que prepararam uma mudança substancial da situação global, atingiram seu desfecho" (ARNAUD, 1999, p.185).

Em geral, não se pode valorar a priori uma crise, positiva nem negativamente, já que ela abre iguais possibilidades para o surgimento de algo benéfico ou maléfico - ou melhor, para o aparecimento de uma época de prosperidade ou de decadência para a entidade que a experimenta. Além disso, toda crise mostra-se essencialmente crítica, uma vez que, de certo modo, procede a uma comparação do período imediatamente anterior a ela (BORNHEIM, 1996, p.61). Na verdade, toda crise destina-se mesmo a "reinventar a realidade" (BORNHEIM, 1996, p.63).

No estudo do fenômeno jurídico parece imprescindível promover o resgate da origem grega do termo, utilizando-o simplesmente para indicar um momento de ruptura no funcionamento do sistema normativo, a partir de uma mudança qualitativa em sentido positivo ou em sentido negativo nos seus elementos e nas relações entre eles. Por tudo isso, a idéia de crise deve ser utilizada sem qualquer sentido pejorativo, designando tão-somente uma fase de transição, ou melhor, de superação de paradigmas ou modelos normativos, podendo gerar tanto um período de progresso como um período de decadência.

\section{Em busca da legitimidade do direito civil: a revolta dos fatos contra o código}

O estudo da crise do direito civil torna-se infecundo quando não ligado aos diversos fenômenos sociais que compõem a comunidade que aquele setor da disciplina jurídica pretende regular (TOBEÑAS, 1961, p.7-9). 
A convivência em qualquer ambiente social depende da existência de normas que disciplinem as diversas relações possíveis entre os seus membros, o que parece ser alcançado precipuamente a partir do estabelecimento de normas jurídicas, tendo em vista a reforçada pretensão de efetividade dessas. Chega-se a afirmar, com acerto, que o ordenamento jurídico é mesmo inerente à vida dos seres humanos em sociedade.

Para cumprir sua função, as normas jurídicas devem atender às necessidades e expectativas dos membros de determinada comunidade, refletindo a síntese dos sentimentos de juridicidade então vivenciados naquela organização social. Como muito bem observado por Eros Roberto Grau, podemos claramente identificar um conjunto de sentimentos dotados de certa juridicidade que se irradiam das próprias interações sociais (GRAU, 2002, p.77), cabendo ao legislador absorvê-los e, conseqüentemente, transformá-los em direito positivo, pois este somente será considerado legítimo quando "produzido com autoridade, de modo a expressar os padrões de cultura, ou seja, os sentidos forjados pela sociedade como expressões das aspirações e rumos que ela, sociedade, pretende seguir" (GRAU, 2002, p.88).

A legitimidade das normas jurídicas não pode mais se limitar à mera legalidade. De fato, um direito positivo, fundado exclusivamente na vontade arbitrária de um legislador supostamente onipotente, desapegado completamente dos valores, sentimentos, necessidades e expectativas compartilhados pelos membros de determinado grupamento social, torna-se um direito ilegítimo e até mesmo ineficaz ou impotente - o que, por sua vez, pode dar ensejo a um verdadeiro caos social.

Aliás, interessante destacar que a legitimidade das normas jurídicas não é aferível apenas no momento de sua produção, mas também na ocasião de sua aplicação. Adverte Orlando de Carvalho que "nenhum direito ou ramo do direito admite uma paralisação no tempo: mesmo que as normas não mudem, muda o entendimento das normas, mudam os conflitos de interesses que se têm de resolver, mudam as soluções de direito, que são o direito em ação" (CARVALHO, 1981, p.50). Durante todo seu período de vigência, as normas jurídicas devem apresentar-se compatíveis com os padrões de juridicidade de determinado grupamento social, sob pena de configuração de sua ilegitimidade superveniente.

Por tudo isso não se pode esquecer que a visualização do fenômeno jurídico, sob a perspectiva reducionista da norma, é mesmo parcial e incompleta (GRAU, 2002, p.19). O direito civil, assim como as demais facetas do fenômeno jurídico, é produto histórico e cultural, construído no cotidiano dos indivíduos.

A propósito, leciona Francisco Amaral:

A compreensão do que seja realmente o fenômeno jurídico não deve partir da visão do direito como simples conjunto de normas ou como determinado procedi- 
mento de solução de conflitos de interesses, mas da certeza de ser ele produto de uma realidade complexa e dinâmica, que é a vida em sociedade, com seus problemas e controvérsias (AMARAL, 2000, p.6).

E acrescenta o autor:

Creio ser impossível uma perfeita compreensão do fenômeno jurídico, principalmente do direito civil, sem recurso à investigação histórica, que permite identificar os fatores que nele vêm influindo, ao longo do seu processo de formação, principalmente os que se verificam no seu estágio atual de profundas transformações. [...] As estruturas jurídicas não são neutras, e os sistemas de direito não se constituem em instrumentos técnicos para fins de qualquer natureza, mas para a realização dos valores essenciais da sociedade de que emergem. O estudo do direito civil e, particularmente do direito civil brasileiro, deve, portanto, levar em conta a realidade que o produz, não somente os aspectos formais de suas instituições, pois o direito se torna incompreensível com o exame apenas de suas normas e sem a necessária perspectiva histórica e social (AMARAL, 2000, p.108-109).

O direito civil, portanto, não encerra uma estrutura neutra, mas dinâmica, que acompanha a evolução da comunidade na qual está inserido. Mais que isso, não deve ser entendido como uma mera representação da realidade social, externo a ela, mas como um dos seus componentes. Deve-se perceber que o direito civil não está imune às ações dos outros elementos formadores da estrutura social, mas com eles mantém uma constante relação de tensão, sendo que alterações de ordem política, econômica, social ou ética podem muito bem repercutir no seu terreno.

Quando mudam as condições de vida parece inevitável também a alteração das ações jurídicas, para que se possa assegurar uma ordem social melhor (TOBEÑAS, 1961, p.54). Noutros termos, na medida em que os interesses e as necessidades dos membros de determinado agrupamento social se alteram, por quaisquer motivos, legitima-se, conseqüentemente, a mudança do modelo vigente de direito civil. Não se pode desejar explicar e tutelar novas situações jurídicas - como aquelas envolvendo os embriões criopreservados ou os contratos eletrônicos - com institutos jurídicos concebidos no pretérito, quando nem mesmo se cogitava a existência dessas situações.

O contexto de inserção da sociedade contemporânea é bem diverso daquele sob o qual se construiu o modelo codificado de direito civil. No Brasil, por exemplo, a população cresceu de maneira surpreendente. Em 1900, estima-se que era composta por pouco mais de 17 milhões de pessoas - em 2000, aproximava-se de 170 milhões. Em 1940, menos de 30\% dos brasileiros viviam nas cidades - em 2000, mais de $80 \%$ ocupavam os centros urbanos. Em 1900, cerca de $60 \%$ da população 
economicamente ativa se dedicavam à agricultura e ao extrativismo, enquanto apenas $5 \%$ estavam alocados nas atividades industriais - em 1990, aproximadamente $80 \%$ do segmento economicamente ativo estavam vinculados às atividades industriais e serviços, sendo responsável por cerca de $90 \%$ da produção da riqueza nacional (vide IBGE, 1990; IBGE, 2001). Presenciamos transformações de várias ordens, que modificaram substancialmente a fisionomia social, tornando-a bem mais complexa, aberta, plural e dinâmica. A sociedade contemporânea é marcada, entre outros fatores, pela mundialização da economia, pelo domínio do conhecimento e rapidez da informação, pelo espantoso desenvolvimento tecnológico, pelos diversos desafios de melhoria das condições básicas de convivência social.

Por todo o exposto, parece evidente que a crise do direito civil nada mais é do que a repercussão na esfera jurídica das transformações verificadas na nossa atual sociedade, pois "a complexidade dos fatores que determinam a mudança da sociedade atingem, reflexamente, o direito que experimentamos em nossos dias" (TOBEÑAS, 1961, p.10).

O direito civil está em crise, pois sua conformação tradicional - projetada pelo movimento de codificação - não consegue mais dar respostas adequadas às emergentes demandas da sociedade contemporânea. Ocorre a "revolta dos fatos contra o Código" (FACHIN, 2000a, p.324).

\section{Superação do modelo codificado: a indispensabilidade do direito civil e sua razão antropocêntrica}

Não se pode deixar de reconhecer que a superação de certo modelo de manifestação do direito civil não tem o condão de, reflexamente, determinar o desaparecimento do próprio direito civil (TOBEÑAS, 1961, p.48). "A modificação das regras e das instituições de direito civil para ampliá-las ou restringi-las em razão das mudanças sociais, não quer dizer que esteja este dito direito em fase de destruição ou desaparecimento" (TOBEÑAS, 1961, p.75-76).

A propósito ${ }_{2}$ adverte Antônio Hernandez Gil:

A expressão crise do direito civil tem-se generalizado perigosamente; a meu juízo, infundadamente. Os que assim pensam, o fazem em nome de um relativismo histórico. E o erro que todos cometem passa por uma falta de perspectiva histórica. De um lado, porque consideram como o único direito civil possível o que se mostra como tal na penúltima etapa de sua evolução; e assim, toda mudança posterior, toda falta de coincidência, se concebe como negação da existência, perecimento, antítese, extinção. E de outro lado, porque não delimitam cuidadosamente aquilo 
que no direito civil há de substancial daquilo outro que é secundário, perfeitamente mutável, sem comprometer a essência do direito civil (GIL, 1958, p.20).

Com isso quer-se enfaticamente afirmar que a crise do direito civil, tomada em sentido positivo ou negativo, não leva ao declínio ou desaparecimento do direito civil, pois este se destina a regular a convivência social, disciplinando os aspectos mais íntimos e corriqueiros da vida do ser humano e, como esta evolui com o transcurso do tempo, faz-se necessário que as manifestações jurídicas se adaptem a ela, para que não fiquem completamente inoperantes. $\mathrm{O}$ direito civil é inerente à vida em sociedade, sendo que, enquanto houver necessidade de os indivíduos interagirem com seus pares, torna-se imprescindível sua existência.

Neste sentido, aponta José Castán Tobenãs:

Como as normas jurídicas deste [do direito civil] não têm outra finalidade que a de regular o mais justamente possível a vida humana, e esta evolui de uma maneira constante com o transcurso do tempo, é necessário que as manifestações da ação jurídica se adaptem a ela, o que equivale a dizer que, se não o direito em si mesmo, as manifestações positivas deste também têm que evoluir, a fim de não ficarem completamente inoperantes e produzirem uma absoluta disparidade entre a teoria e a prática, até o ponto de que podemos dizer que o ordenamento jurídico mais perfeito será aquele que melhor assimile as contínuas modificações que experimenta periodicamente a vida social. [...] Não há tal agonia do direito civil, nem ontem nem agora, pois facilmente se percebe que se existe um ramo jurídico que não pode desaparecer de nenhuma maneira é precisamente este, por estar dedicado a regular a esfera mais íntima do indivíduo, é dizer, seu nascimento, seu matrimônio, sua família, sua propriedade, sua vida contratual, sua morte e seu patrimônio hereditário, pelo que, quaisquer que sejam as vicissitudes pelas quais possa passar a sociedade, enquanto haja seres humanos sobre a Terra, existirá direito civil, encarregado de regular entre eles as relações de caráter privado, sem o que seria completamente impossível a convivência social (TOBEÑAS, 1933, p.13-18).

As alterações sofridas pelo direito civil constituem, por um lado, os sinais inevitáveis do aparecimento da crise de seu modelo codificado e, por outro lado, as primeiras respostas para a superação deste mesmo modelo normativo, com a conseqüente inauguração do seu paradigma pós-moderno ou contemporâneo. Este ramo jurídico não desaparece, somente se transforma com o transcurso dos séculos, como tudo na vida.

Por sua vez, parece que a despontada crise do direito civil, pelos menos para os mais lúcidos, não vem carregada de negatividade, pois se configura como a superação de paradigma jurídico que não mais se apresenta consentâneo com os atuais 
anseios sociais. A crise abre, portanto, as portas para a renovação do direito civil, com sua conseqüente preservação. $O$ direito civil está em pleno vigor, em verdadeira efervescência, preparando-se continuamente para acompanhar os mais urgentes reclamos sociais (TOBEÑAS, 1933, p.5).

A atual crise do direito civil, antes de indicar seu enfraquecimento ou até mesmo seu desaparecimento, realça a sua vitalidade, uma vez que não se pode esquecer que o fenômeno jurídico é essencialmente histórico e, conseqüentemente, em constante mutação, tendo em vista as incessantes exigências de harmonização do convício social.

Obviamente, não há como determinar com exatidão a nova fisionomia da disciplina civilística; no entanto, as mais relevantes tendências apontam para a personalização do direito civil, isto é, pela busca da raiz antropocêntrica deste setor da disciplina jurídica, que de mais perto convive com a intimidade dos seres humanos e seus afazeres mais corriqueiros. Esse movimento "reencontra a trajetória da longa história da emancipação humana, no sentido de repor a pessoa humana como centro do direito civil, passando o patrimônio ao papel coadjuvante, nem sempre necessário" (LÔBO, 1999, p.103), assim projetando uma evidente discussão sobre os valores que o sistema jurídico colocou em seu centro e em sua periferia, ontem e hoje (FACHIN, 2000a, p.74-75).

Sob o manto de uma pretensa neutralidade, nosso primeiro Código Civil acabou privilegiando o patrimônio como valor necessário da plena realização da pessoa (FACHIN, 2000a, p.55). O ser humano era valorizado pela sua aptidão para ter patrimônio e não por sua dignidade como tal. Assim, o Código serviu para atender aos interesses de uma classe social bem-definida, que pretendia essencialmente otimizar com segurança suas relações de aquisição, transmissão e manutenção de bens, aparecendo como protetor dos valores econômicos, especialmente daqueles incidentes sobre bens corpóreos, não guardando espaço adequado para a tutela dos valores existenciais do ser humano.

O Código Civil reconheceu a pessoa como "um homem que resume todos os seus direitos a possuir e a saber como possuir", assim ignorando o "homem concreto, o homem de carne, sujeito a debilidades, presa de necessidades, esmagado por forças econômicas" (CARVALHO, 1981, p.33-34). A própria sistemática de exposição de suas normas evidenciou esse certo desprezo pela dimensão concreta do ser humano, reduzindo-o, tal como as coisas e os fatos, sem qualquer específica posição de privilégio, a um simples elemento da categoria abstrata da relação jurídica (CARVALHO, 1981, p.48). Ser sujeito de direito dependia do enquadramento do indivíduo naquelas hipóteses previamente dispostas na lei, que coordenavam e limitavam sua atuação nas relações sociais. 
Hoje já não pode ser mais assim. A instauração da nossa ordem constitucional vigente consolidou certa subversão axiológica no âmbito do direito civil, que desde o segundo pós-guerra vinha se operando timidamente através das leis especiais. Ontem o patrimônio recebia proteção prioritária; hoje, a dignidade da pessoa humana.

Ao enunciar, no seu dispositivo introdutório, que a dignidade da pessoa humana constitui o fundamento de nossa sociedade e, conseqüentemente, de todo nosso ordenamento jurídico, o texto constitucional exaltou o suporte normativo que possibilita a reconstrução axiológica e sistemática do direito civil. Afinal, como bem observou Orlando de Carvalho, um direito civil que não arranque da pessoa humana é um direito civil sem sentido, tornando-se mesmo imprescindível acentuar sua raiz antropocêntrica, sua ligação visceral com a pessoa e as suas intrínsecas necessidades (CARVALHO, 1981, p.90-91).

A exaltação axiológica da dignidade da pessoa humana tem levado o direito civil a sofrer um processo de despatrimonialização, através do qual se evidencia sua maior sensibilidade às situações existenciais, que recolhem dados não-confináveis nos esquemas normativos de índole econômica (PERLINGIERI, 1991, p.55). Mais do que isso, destaca-se progressivamente a maior importância atribuída aos interesses personalíssimos, em detrimento daqueles patrimoniais, como evidenciado na tutela dos direitos de personalidade. Não se projeta, contudo, a expulsão ou a redução quantitativa do conteúdo patrimonial do sistema jurídico civilístico, mas se reconhece que os bens e os interesses patrimoniais não constituem fins em si mesmos, devendo ser tratados como meios para a realização da pessoa humana, ou melhor, como justificativa institucional de suporte ao livre desenvolvimento da pessoa (PERLINGIERI, 1991, p.55).

Nesse sentido, adverte Paulo Luiz Netto Lôbo:

O desafio que se coloca aos civilistas é a capacidade de ver as pessoas em toda a sua dimensão ontológica e, através dela, seu patrimônio. Impõem-se a materialização dos sujeitos de direitos, que são mais que apenas titulares de bens. A restauração da primazia da pessoa humana, nas relações civis, é condição primeira de adequação do direito civil à realidade e aos fundamentos constitucionais (LÔBO, 1999, p.103).

Tendo em vista todo o exposto, reforçamos nosso entendimento sobre a inoportuna promulgação do novo Código Civil, uma vez que esse ostensivamente reproduziu o perfil patrimonialista e conceitualista do seu antecessor, em evidente desacordo e afronta às escolhas axiológicas de nossa ordem constitucional (vide FACHIN, 2000b; ROBERTO, 2008). 
Contudo, não se deve sucumbir ao pessimismo e ao desânimo. Cabe ao intérprete a defesa do tratamento evolutivo que tem caracterizado as relações privadas na contemporaneidade, salvaguardando os interesses inerentes à dignidade da pessoa humana.

Um direito civil para todos. Um direito civil mais humanizado, atendendo as aspirações do projeto de vida e felicidade de cada ser humano, sem descuidar de sua dimensão solidária. Este é o nosso desafio. Este é o desenho que temos que continuar a pintar.

\section{Referências}

AMARAL, Francisco. Direito civil. 3. ed. Rio de Janeiro: Renovar, 2000. ARNAUD, André-Jean et al. Dicionário enciclopédico de teoria e de sociologia do direito. 2. ed. Rio de Janeiro: Renovar, 1999.

AZEVEDO, Antônio Junqueira de. O direito civil tende a desaparecer? Revista dos Tribunais. São Paulo, ano 64, n. 472, fev. 1975, p.15-21.

BORNHEIM, Gerd. Crise da idéia de crise. In: NOVAES, Adauto (org.). A crise da razão. São Paulo: Companhia das Letras, 1996, p. 47-66.

CARVALHO, Orlando de. Para uma teoria da relação jurídica civil. 2. ed. Coimbra: Centelha, 1981.

DE CUPIS, Adriano. La crisi dei valori del diritto civile. Rivista di Diritto

Civile. Padova, anno 32, n. 2, parte 1, mar./apr. 1986, p. 191-204.

FACHIN, Luiz Edson. Teoria crítica do direito civil. Rio de Janeiro: Renovar, 2000a.

. Sobre o projeto do código civil brasileiro: crítica à racionalidade

patrimonialista e conceitualista. Boletim da Faculdade de Direito. Coimbra, n.76, jan./dez. 2000b, p. 129-151.

GIORGIANNI, Michele. O direito privado e as suas atuais fronteiras. Revista dos Tribunais. São Paulo, ano 87, v. 747, jan. 1998, p. 35-55.

GRAU, Eros Roberto. O direito posto e o direito pressuposto. 4. ed. São Paulo: Malheiros, 2002.

HERNANDEZ GIL, António. Reflexiones sobre el futuro del derecho civil. Madrid: Ateneo, 1958.

IBGE. Estatísticas históricas do Brasil. Rio de Janeiro: IBGE, 1990.

IBGE. Síntese de indicadores sociais 2000. Rio de Janeiro: IBGE, 2001. 
LÔBO, Paulo Luiz Netto. A constitucionalização do direito civil. Revista de Informação Legislativa. Brasília, ano 36, n. 141, jan./mar. 1999, p. 99-109. PERLINGIERI, Pietro. Il diritto civile nella legalità costituzionale. 2. ed. Napoli: Scientifiche Italiane, 1991.

RIPERT, Georges, et al. La crisis del derecho. Buenos Aires: Europa-America, 1953.

ROBERTO, Giordano Bruno Soares. Introdução à história do direito privado e da codificação: uma análise do novo código civil. 2. ed. Belo Horizonte: Del Rey, 2008.

TOBEÑAS, José Castán. Crisis mundial y crisis del derecho. 2. ed. Madrid: Reus, 1961.

. Hacia un nuevo derecho civil. Madrid: Reus, 1933. 